Check for updates

Cite this: RSC Adv., 2017, 7, 40952

Received 4th June 2017

Accepted 7th August 2017

DOI: $10.1039 / \mathrm{c} 7 \mathrm{ra06223k}$

rsc.li/rsc-advances

\section{Acid-assisted hydrothermal synthesis of red fluorescent carbon dots for sensitive detection of $\mathrm{Fe}(\mathrm{III}) \dagger$}

\author{
Chunlin Tan, (D) ${ }^{\text {ac }}$ Xiuya Su, ${ }^{\text {ad }}$ Chao Zhou, ${ }^{\text {a }}$ Baoju Wang, ${ }^{\text {a }}$ Qiuqiang Zhan*a \\ and Sailing $\mathrm{He}^{\star a b}$
}

Red-emitting carbon dots ( $C$-dots) were synthesized from $p$-phenylenediamine ( $p$-PD) aqueous solution with nitric acid $\left(\mathrm{HNO}_{3}\right)$ assistance by hydrothermal reaction at $200{ }^{\circ} \mathrm{C}$ for $2 \mathrm{~h}$. p-PD aqueous solution can be transferred to $\mathrm{C}$-dots (or poly(p-PD)) with (or without) the addition of acid. Different acid systems, such as $\mathrm{HNO}_{3}, \mathrm{H}_{3} \mathrm{PO}_{4}$ and $\mathrm{HF}$, can directly synthesize red-emitting $\mathrm{C}$-dots, and the fluorescence can be enhanced by increasing the strength of acids. N-CDs, $3.46 \mathrm{~nm}$-average-sized $\mathrm{C}$-dots, prepared in dilute $\mathrm{HNO}_{3}$, have a quantum yield of $15.8 \%$ with unique, excitation-wavelength independent emission in the red region (600 and $680 \mathrm{~nm}$ ) and a broad visible excitation band. Carboxyl, ester and hydroxyl groups on the C-dots surface directly lead to red emission. N-CDs have a certain selective specificity for $\mathrm{Fe}^{3+}$ detection and the linear range is $10-300 \mathrm{nmol} \mathrm{L} \mathrm{L}^{-1}$ with a limit of determination of $1.9 \mathrm{nmol} \mathrm{L}^{-1}$

\section{Introduction}

Emerging as a new class of zero-dimensional nano-materials, carbon dots (C-dots) have been widely studied during the past decade. Thanks to their advantages including excellent water solubility, optical stability, unique fluorescence properties, low toxicity, low cost, etc., ${ }^{1} \mathrm{C}$-dots can be applied in various fields, such as electrochemical immune-sensors, ${ }^{2}$ bio-imaging, ${ }^{3,4}$ sensors, ${ }^{5}$ photo-catalysis ${ }^{6}$ and optoelectronics. ${ }^{7}$

Various synthesis methods have been developed since carbon dots were discovered, ${ }^{8}$ and they can be mainly categorized into "top-down" and "bottom-up" routes. ${ }^{9}$ This classification is mainly based on carbon sources. The "top-down" route physically decomposes macro carbon materials into smaller and smaller nano materials, while the "bottom-up" route chemically creates C-dots by molecular self-assembly reactions from various small molecular reagents. Most of the "bottomup" routes are efficient to prepare C-dots on a large scale ${ }^{10}$ and the carbon sources are widely available from various natural

${ }^{a}$ Centre for Optical and Electromagnetic Research, South China Academy of Advanced Optoelectronics, South China Normal University, 510006 Guangzhou, China. E-mail: zhanqiuqiang@m.scnu.edu.cn; sailing@jorcep.org

${ }^{b}$ JORCEP, Department of Electromagnetic Engineering, Royal Institute of Technology, 10044 Stockholm, Sweden

${ }^{c}$ Centre for Editorial and Publishing Research, South China Normal University, 510006 Guangzhou, China

${ }^{d}$ School of Physics and Telecommunication Engineering, South China Normal University, 510006 Guangzhou, China

$\dagger$ Electronic supplementary information (ESI) available. See DOI: $10.1039 / \mathrm{c} 7 \mathrm{ra} 06223 \mathrm{k}$ products (fruit juice, ${ }^{11-14}$ dried grass, ${ }^{15} e t c$.) and small organic molecules. ${ }^{16}$ Because of the complex composition of natural products, the photoluminescence (PL) mechanism for C-dots need further study, and thus small molecular carbon sources have become hot research in recent years.

Isomers of phenylenediamine (PD), $o-, m-$, and $p$-PD, had been studied as a new carbon source for preparing $o$-CDs,,${ }^{5,17,18}$ $m$-CDs, ${ }^{16}$ and $p$-CDs, ${ }^{16,19}$ respectively, among which $o$-PD and $m$-PD are relatively easy to form C-dots, while there is challenge in employing $p$-PD. $p$-PD has been studied and proposed as a carbon source since $2015,{ }^{17}$ and the as-prepared $p$-CDs emit red fluorescence. After that, Ding et al. ${ }^{19}$ prepared full-colour C-dots from $p$-PD aqueous solution and urea, and utilized a complex separation process of silica gel column chromatography. However, the process of silica gel column chromatograph is laborious and solvent-, time-, and cost-consuming. The disadvantages of low efficiency, low yield, and high cost of the preparation and separation limit the further applications of $p$-CDs. Metal ions, especially for transition metal ions, are toxic and hard to recycle in wastewater, surface water and ground water. ${ }^{20}$ Therefore, it is necessary to develop an efficient metal ions sensor.

Herein, we report a one-pot synthesis for red emitting C-dots from $p$-PD in the assistance of acids. Among the different inorganic acids, such as $\mathrm{H}_{3} \mathrm{PO}_{4}, \mathrm{HNO}_{3}$, and $\mathrm{HF}$ etc., $\mathrm{HNO}_{3}$ were found to be efficient to prepare red C-dots (labelled as N-CDs). These $\mathrm{C}$-dots possess unique optical properties. The as-prepared N-CDs can be directly used as a sensor to detect metal ions, and they are sensitive for $\mathrm{Fe}^{3+}$ sensing at a range of $10-300 \mathrm{nmol} \mathrm{L}^{-1}$ with the limit of determination (LOD) of $1.9 \mathrm{nmol} \mathrm{L}^{-1}$. 


\section{Experimental section}

\subsection{Experimental materials}

p-PD, hexane, and ethyl alcohol were purchased from Aladdin Co., China. The concentrated acids of $\mathrm{HNO}_{3}, \mathrm{HF}, \mathrm{H}_{3} \mathrm{PO}_{4}$ were purchased from Sinopharm Chemical Reagent Co., China. $\mathrm{KCl}$, $\mathrm{CaCl}_{2}, \mathrm{Mg}\left(\mathrm{NO}_{3}\right)_{2}, \mathrm{Al}\left(\mathrm{NO}_{3}\right)_{3}, \mathrm{Zn}\left(\mathrm{NO}_{3}\right)_{2}, \mathrm{FeCl}_{3}, \mathrm{SnCl}_{2}, \mathrm{~Pb}\left(\mathrm{NO}_{3}\right)_{2}$, $\mathrm{CuCl}_{2}, \mathrm{AgNO}_{3}, \mathrm{CoCl}_{2}, \mathrm{NiCl}_{2}, \mathrm{MnCl}_{2}, \mathrm{InCl}_{3}, \mathrm{Cd}\left(\mathrm{NO}_{3}\right)_{2}$ and $\mathrm{Cr}\left(\mathrm{NO}_{3}\right)_{2}$, were purchased from Aladdin Ltd., China. All the reagents were used without purification. Deionized (DI) water was used in the whole experimental procedures.

\subsection{Synthesis of CDs}

Several parameters, such as different acids, molar ratio of $c($ acid $): c(p-\mathrm{PD})$, reaction temperature $(T)$, reaction time $(t)$, were concerned to optimize the experimental conditions. Firstly, mixture aqueous solutions of $0.1 \mathrm{~mol} \mathrm{~L}^{-1} p$-PD and acid solution $\left(\mathrm{HNO}_{3}, \mathrm{H}_{3} \mathrm{PO}_{4}\right.$ or $\left.\mathrm{HF}\right)$ with controlled concentration of $x$ mol L ${ }^{-1}$ were sealed into Teflon-lined autoclave, heated up to $200{ }^{\circ} \mathrm{C}$ inside a constant temperature oven keeping for $2 \mathrm{~h}$, and then naturally cooled to room temperature. The $c$ (acid) for the brightest and reddest C-dots under $365 \mathrm{~nm}$ UV light (PL assessment, see Fig. S1†) was optimized. Secondly, solutions with $y \mathrm{~mol} \mathrm{~L}^{-1} p$-PD and $c$ (acid) acid were treated as the first step and then the optimal mole ratio was obtained by PL assessment. Thirdly, keeping the optimal mole ratio and other conditions constant and changing $c(p$-PD) from 0.02 to $0.20 \mathrm{~mol} \mathrm{~L}^{-1}$, then the optimal ratio was refined and the range of $c(p-\mathrm{PD})$ for the preparation of red C-dots was obtained. At last, fixing the refined ratio and other conditions, the reaction temperature $T$ was varied from $140{ }^{\circ} \mathrm{C}$ to $220^{\circ} \mathrm{C}$. Similarly, the reaction time $t$ was also optimized ranging from $2 \mathrm{~h}$ to $8 \mathrm{~h}$. The optimized experimental parameters, such as the molar ratio, $T$ and $t$, were finally confirmed (see Fig. S2 $\dagger$ ). As a contrast, $p$-PD aqueous solution $\left(0.1 \mathrm{~mol} \mathrm{\textrm {L } ^ { - 1 }}\right)$ without acid adding was hydrothermally reacted at $200{ }^{\circ} \mathrm{C}$ for $2 \mathrm{~h}$. Samples prepared by $p$-PD aqueous solutions with $\mathrm{HNO}_{3}, \mathrm{H}_{3} \mathrm{PO}_{4}, \mathrm{HF}$, and without acid adding, were labelled as N-CDs, P-CDs, F-CDs, and Pp-PD, respectively. For the purification (see Table $\mathrm{S} 1 \dagger$ ), the crude products of N-CDs were successively washed (by hexane to remove the unreacted $p$-PD), centrifuged (at $14000 \mathrm{rpm}$ for $30 \mathrm{~min}$ to remove polymer precipitation), and filtered (through a $0.22 \mu \mathrm{m}$ filter membrane). The final concentration of the obtained N-CDs was determined by weighting the mass the dried powder of the corresponding C-dots solution sample.

\subsection{Quantum yield measurements}

Quantum yields (QYs) of the C-dots were determined by a relative measurement method. ${ }^{17,21}$ Specially, Rhodamine B (QYs $=56 \%$ in ethanol) was selected as the reference dye for the emission range of 580-610 nm excited by $365 \mathrm{~nm}$ UV light. The QYs was calculated by

$$
\phi=\phi^{\prime} \times \frac{A^{\prime}}{I^{\prime}} \times \frac{I}{A} \times \frac{n^{2}}{n^{\prime 2}}
$$

where $\phi$ and $\phi^{\prime}$ are the QYs of sample and reference dye, $I$ and $I^{\prime}$ are the integrated emission intensity of the sample and dye, $n$ and $n^{\prime}$ are the refractive indexes $\left(1.33\right.$ for $\mathrm{H}_{2} \mathrm{O}$ and 1.36 for ethanol) of sample and dye. A series of C-dots solution samples and the reference dye were prepared with proper concentrations to ensure the light absorbance $A<0.1$ at $365 \mathrm{~nm}$. The QYs values were then obtained by comparing the integrated PL intensities $v s$. absorbance curves.

\subsection{Characterization}

High-resolution TEM (HR-TEM) images were recorded on transmission microscope (JEM-2100HR, JEOL) operating at $200 \mathrm{kV}$. FT-IR spectra of C-dots solutions were collected using FT-IR spectrometer (IRPrestige-21, SHIMADZU) by use of KRS-5 window slices (mixture of TlBr and TII). Typically, liquid phases were dropped on one slice and dried. The slice was covered by the other slice and fixed on the testing stand, then the infrared spectra recorded.

\subsection{Optical measurements}

The fluorescence spectra of C-dots were measured using a fluorescence spectrophotometer (F-2500, HITACHI). UV-Vis absorption spectra were recorded on using UV/VIS/NIR Spectrometer (Lambda 950, Perkin Elmer).

\subsection{Detection of metal ions}

The fluorescence intensity of the N-CDs sample is concentration dependent and reaches its highest value at $0.1 \mathrm{mg} \mathrm{mL} \mathrm{m}^{-1}$. Therefore, the concentration of C-dots for metal ions sensing is set up at $0.1 \mathrm{mg} \mathrm{mL} \mathrm{m}^{-1}$. The as-prepared $\mathrm{N}$-CDs solution $\left(9.6 \mathrm{mg} \mathrm{mL}^{-1}\right.$,

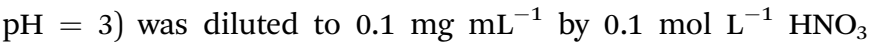
solution, and all the metal ion solutions were prepared and diluted step-wise with $0.1 \mathrm{~mol} \mathrm{~L}{ }^{-1} \mathrm{HNO}_{3}$ solution to the concentrations of interest. Herein, $0.1 \mathrm{~mol} \mathrm{~L}^{-1} \mathrm{HNO}_{3}$ solution was used for two reasons. The one is intended to build a method of metal ions sensing with purification-free C-dots, and the other is to avoid the hydrolysis of some unstable ions, such as $\mathrm{Sn}^{2+}, \mathrm{Mn}^{2+}$, etc.

Selective sensing experiments for metal ions were carried out by fluorescence intensity quenching method. Typically, $200 \mu \mathrm{L}$ of different metal ion solutions $\left(1 \mu \mathrm{mol} \mathrm{L}{ }^{-1}\right)$ or blank sample (0.1 mol L ${ }^{-1} \mathrm{HNO}_{3}$ solution) were added into $1800 \mu \mathrm{L} \mathrm{N}$-CDs solutions ( $\left.1 \mathrm{mg} \mathrm{mL}^{-1}\right)$ to prepare a serious testing solutions $\left(M^{n+}=100 \mathrm{nmol} \mathrm{L}{ }^{-1}\right.$, blank $\left.=0 \mathrm{nmol} \mathrm{L}^{-1}\right)$. After incubated at $30{ }^{\circ} \mathrm{C}$ for $30 \mathrm{~min}$, fluorescence of all incubated solutions were measured at the same excitation wavelength of $510 \mathrm{~nm}$.

For $\mathrm{Fe}^{3+}$ sensing experiments, $1800 \mu \mathrm{L} \mathrm{N}$-CDs $\left(0.1 \mathrm{mg} \mathrm{mL}^{-1}\right)$ and $200 \mu \mathrm{L} \mathrm{Fe}^{3+}\left(0-10 \mu \mathrm{mol} \mathrm{L}{ }^{-1}\right)$ were incubated at $30{ }^{\circ} \mathrm{C}$ for $30 \mathrm{~min}$ prior to fluorescence measurements (excited at $510 \mathrm{~nm}$ ).

\section{Results and discussion}

\subsection{Red C-dots can be prepared from $p$-PD in acidic solutions}

Massive experiments have been performed to optimize the experimental parameters, and the results show that the reproducibility of the proposed synthesis is very high. The best conditions for the preparation of red emitting C-dots are concluded and shown in 
Table 1. The molar ratio of $c($ acid $): c\left(p\right.$-PD) for $\mathrm{HNO}_{3^{-}}, \mathrm{H}_{3} \mathrm{PO}_{4^{-}}$, and HF-assisted synthesis are $2.5,7$, and 62.5, respectively. The best temperature $\left(180-200{ }^{\circ} \mathrm{C}\right)$ and the reaction time $(2 \mathrm{~h})$ are similar. The QYs of N-CDs is the highest (15.8\%) (see Table 1, Fig. S3 $\dagger$ ). In the $\mathrm{HNO}_{3}$-assisted synthesis, $\mathrm{N}$-CDs emit blue light at the higher mole ratio range of 3.75 to 5 and red light at a lower range of 3 to 1.5 (see Fig. S2a $\dagger$ ). When the ratio was fixed to 2.5, all the N-CDs emit red light at the full range $\left(0.02-0.20 \mathrm{~mol} \mathrm{~L}^{-1}\right)$ of $c(p-\mathrm{PD})$ (see Fig. 1). It is worth noting that N-CDs emit turquoises and blue light when the reaction time was increased to $6 \mathrm{~h}$ and above (see Fig. S2a $\dagger$ ). In the $\mathrm{H}_{3} \mathrm{PO}_{3}$-assisted synthesis, all as-prepared P-CDs emit weak red light and show no colour change (see Fig. S1b†). P-CDs are easy to be prepared at a lower temperature $\left(140{ }^{\circ} \mathrm{C}\right)$. However, in general the PL intensities of P-CDs are all weak. In the HF-assisted synthesis, the preparation of F-CDs is acid-consuming and the PL is rich in colour. At the high ratio of 220-500 (see Fig. S2c $\dagger$ ), the as-prepared F-CDs emit blue light. At the lower ratio range of 50-100, the F-CDs emit red light. All the as-prepared C-dots crude products are dark burgundy under day light and emit red under $365 \mathrm{~nm}$ UV light (see Fig. S2d†).

\subsection{TEM characterization and FT-IR analysis}

TEM images of Pp-PD and N-CDs were shown in Fig. 2. There were no C-dots but a large amount of polymer nanosheets

Table 1 The optimized reaction parameters of $p$-PD aqueous solution with different acid systems and the quantum yields of the C-dots aqueous solutions ( $10 \times$ diluted from as-prepared products)

\begin{tabular}{lllllll}
\hline C-dots & Acid & $c($ acid $)(\mathrm{M})$ & $c(p$-PD) $(\mathrm{M})$ & $T\left({ }^{\circ} \mathrm{C}\right)$ & $t(\mathrm{~h})$ & QYs (\%) \\
\hline F-CDs & $\mathrm{HF}$ & 10 & 0.16 & 200 & 2 & 11.5 \\
P-CDs & $\mathrm{H}_{3} \mathrm{PO}_{4}$ & 0.7 & 0.10 & 180 & 2 & 11.7 \\
N-CDs & $\mathrm{HNO}_{3}$ & 0.35 & 0.14 & 200 & 2 & 15.8
\end{tabular}

(a)
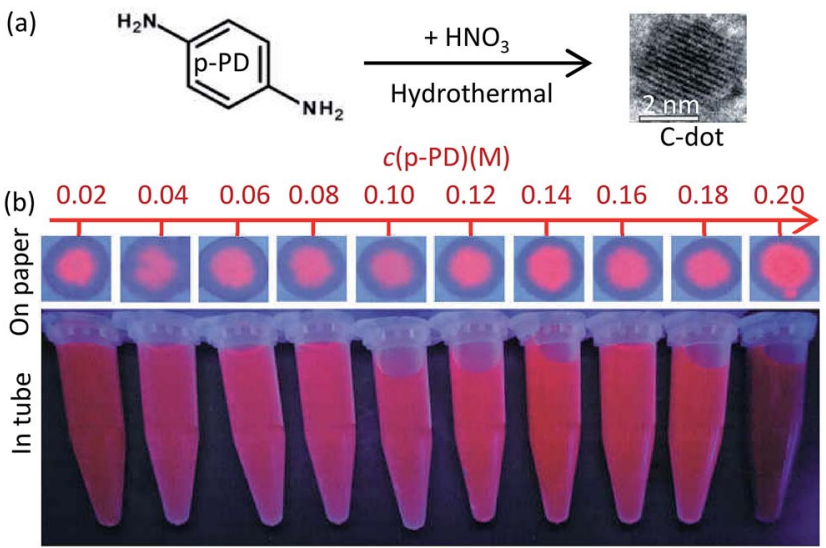

$c\left(\mathrm{HNO}_{3}\right): c(\mathrm{p}-\mathrm{PD})=2.5,200^{\circ} \mathrm{C}, 2 \mathrm{~h}$

Fig. 1 (a) The schematic diagram of N-CDs synthesis. (b) The photographs of $\mathrm{PL}$ spots of as-prepared $\mathrm{N}-\mathrm{CDs}$ aqueous solutions dropped on filter paper (top row) and the N-CDs solutions ( $10 \times$ diluted from as-prepared products) in tubes (bottom row) under $365 \mathrm{~nm}$ UV light.
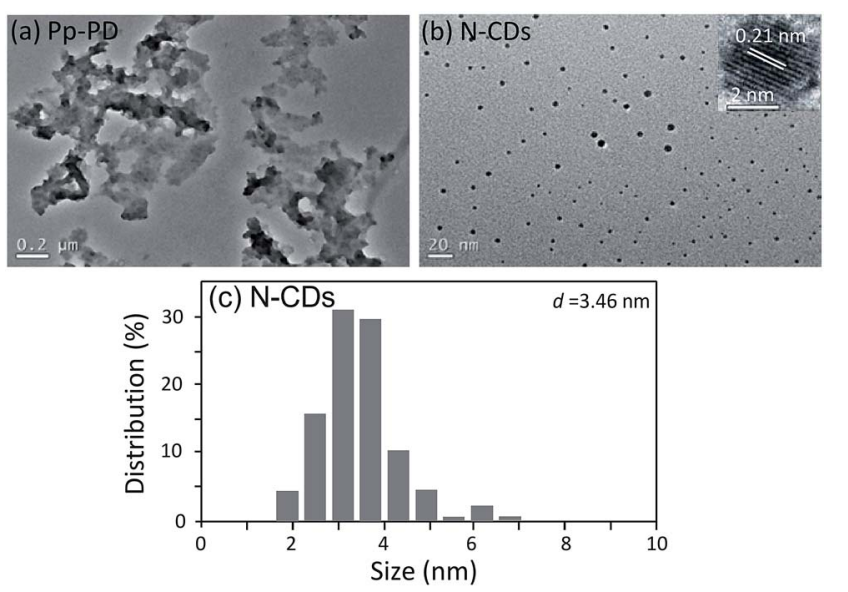

Fig. 2 Reprehensive TEM image of the as-prepared Pp-PD (a) and $\mathrm{N}-\mathrm{CDs}(\mathrm{b})$, the size distribution of N-CDs (c). The distribution was calculated from the TEM image in (b). N-CDs and Pp-PD were prepared by hydrothermal reaction from $p$-PD aqueous solution with and without $\mathrm{HNO}_{3}$ assistance.

formed in the $p$-PD aqueous solution without acid added (see Fig. 2a), while the red-emitting C-dots formed in the assistance of acids. N-CDs, which were prepared from $p$-PD with the assistance of $\mathrm{HNO}_{3}$, are uniform and monodisperse nanodots (see Fig. 2b) with an average diameter of $3.46 \mathrm{~nm}$ (see Fig. 2c). The C-dots exhibit identical well-resolved lattice fringes with a space of $\sim 0.21 \mathrm{~nm}$, corresponding to the (100) in-plane lattice spacing of graphene. ${ }^{22,23}$ It indicates that the addition of acid can inhibit the polymerization process and promoted the formation of nanodots.

Chemical groups on the surface of C-dots may impact the optical properties. From the FT-IR spectra of N-CDs (see Fig. 3), $\mathrm{N}$-CDs contain many groups derived from the precursor, such as $v(\mathrm{Ar}-\mathrm{H})$ (2700-3200 $\mathrm{cm}^{-1}$, belonging to aromatic $\mathrm{C}-\mathrm{H}$ stretching vibration $\left.{ }^{24}\right), \delta(\mathrm{Ar}-\mathrm{H})\left(800-850 \mathrm{~cm}^{-1}\right.$, belonging to aromatic C-H out-of-plane deformation vibration of substituted benzene ring $\left.^{25}\right)$, and $\delta(\mathrm{N}-\mathrm{H})\left(1520 \mathrm{~cm}^{-1}\right.$, belonging to the deformation vibration of $-\mathrm{NH}_{2}$ or $-\mathrm{NH}-$ groups). Other groups, such as $v(\mathrm{O}-$ $\mathrm{H})\left(3500 \mathrm{~cm}^{-1}\right.$, belonging to the deformation vibration of $-\mathrm{OH}$ groups in aliphatic alcohols $), v(\mathrm{C}=\mathrm{O})\left(1600 \mathrm{~cm}^{-1}\right.$, belonging to the stretching vibration of carbonyl in carboxyl groups), and $v(\mathrm{C}-\mathrm{O}-\mathrm{C})\left(1200 \mathrm{~cm}^{-1}\right.$, belonging to the stretching vibration of

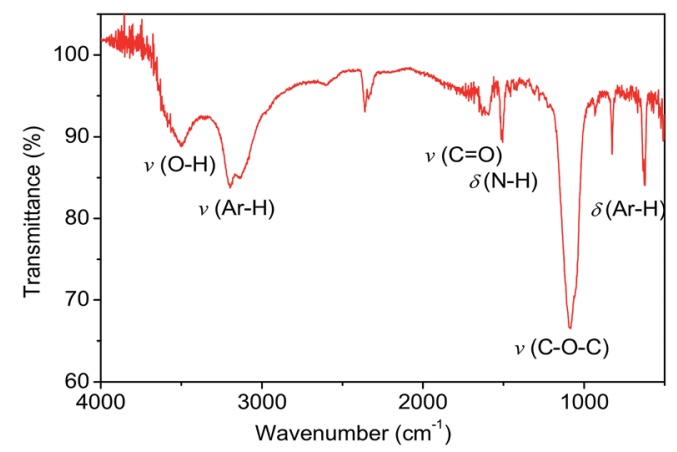

Fig. 3 FT-IR spectra of $\mathrm{N}-\mathrm{CD}$ s prepared from $p-\mathrm{PD}$ and $\mathrm{HNO}_{3}$ solution. 

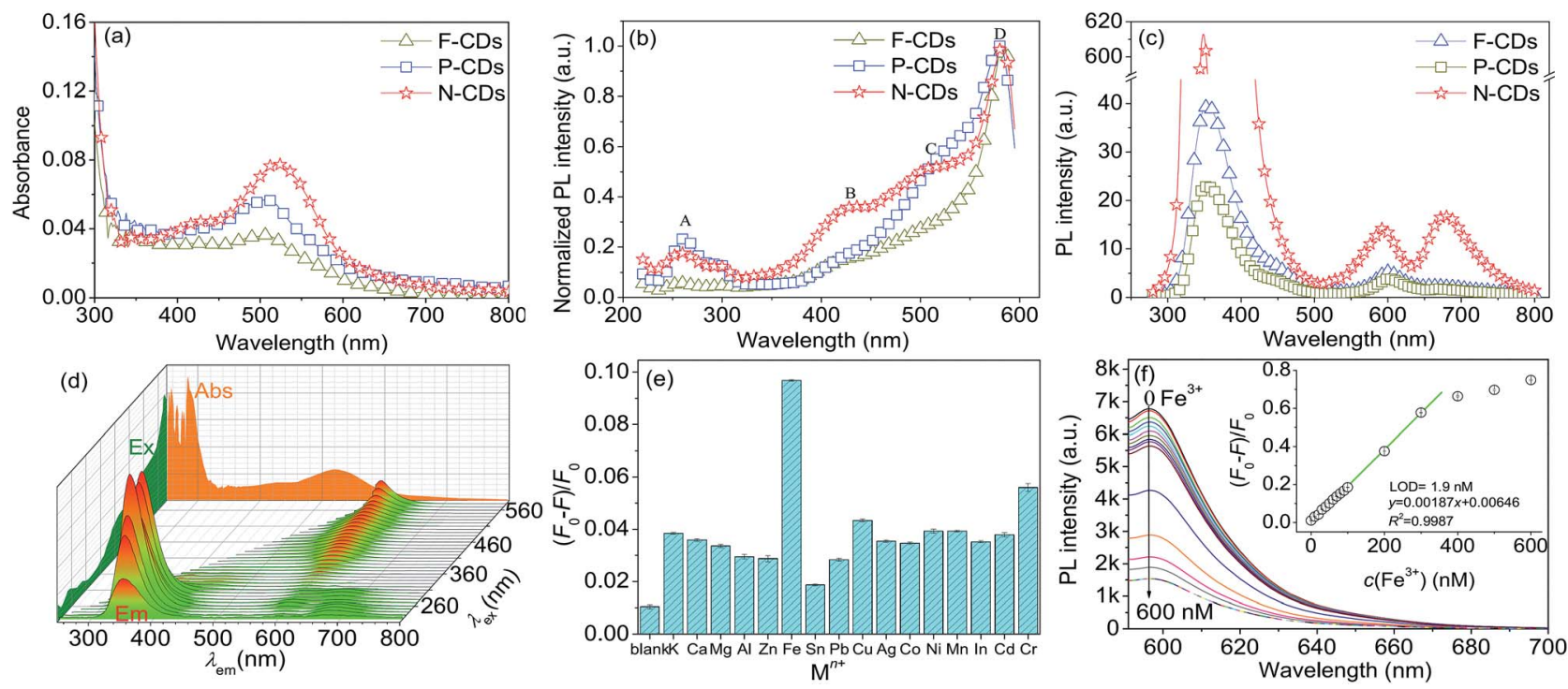

Fig. 4 UV-Vis absorption (a), excitation $\left(\lambda_{\mathrm{em}}=600 \mathrm{~nm}\right.$ ) (b) and emission ( $\lambda_{\mathrm{ex}}=260 \mathrm{~nm}$ ) spectra (c) of different C-dots aqueous solutions $(10 \times$ diluted from as-prepared products), the emission spectra of $\mathrm{N}-\mathrm{CDs}$ aqueous solution (10 $\times$ diluted from the as-prepared product) with the $\lambda_{\text {ex }}=260-580 \mathrm{~nm}(\mathrm{~d})$, the selectivity (e) and the sensitivity (f) of $\mathrm{N}-\mathrm{CDs}\left(0.1 \mathrm{mg} \mathrm{mL}^{-1}\right)$ for the $\mathrm{Fe}^{3+}$ ions sensing in $0.1 \mathrm{~mol} \mathrm{~L}^{-1} \mathrm{HNO}_{3}$ solutions. The concentrations of metal ions are all at $100 \mathrm{nmol} \mathrm{L}^{-1}(\mathrm{e})$, and the $\mathrm{Fe}^{3+}$ concentrations varied at $0,10,20,30,40,50,60,70,80,90,100,200,300$, 400,500 , and $600 \mathrm{nmol} \mathrm{L}^{-1}$ (f). Fluorescence curves of all the samples were measured at the excitation wavelength of $510 \mathrm{~nm}$. The inset in (f) is the linearity of $\mathrm{PL}$ intensity at $580 \mathrm{~nm}$ against the measured $\mathrm{Fe}^{3+}$ concentrations.

ester groups), were formed by ring opening and oxidation reactions.

\subsection{Optical properties}

Although being prepared assisted with different acids, F-CDs, P-CDs and N-CDs showed similar optical properties (see Fig. 4). For UV-Vis spectra, the absorption peaks are located at around 290 and $510 \mathrm{~nm}$, and the absorbance intensities are relatively strong at the range from UV to visible light zone $(350-600 \mathrm{~nm}$, see Fig. 4a). The maximum wavelengths of the absorption peaks at around $510 \mathrm{~nm}$ occurred red-shift in the order of F-CDs, P-CDs, and N-CDs, this is due to the gradually increasing of acidity and oxidation of acids that added in the precursors. For excitation, there are 4 obvious peaks (A: $260 \mathrm{~nm}, \mathrm{~B}: 430 \mathrm{~nm}, \mathrm{C}: 510 \mathrm{~nm}$ and D: $580 \mathrm{~nm}$ ) in N-CDs while several peaks are less prominent in F-CDs and P-CDs samples, and all CDs can be excited at a maximum wavelength of $580 \mathrm{~nm}$ (see Fig. 4b). It indicates that $\mathrm{N}$-CDs have a broad and efficient excitation band in the visible region. For emission, being excited at the same wavelength (260 nm), F-CDs and P-CDs emit at 355 and $600 \mathrm{~nm}$, while N-CDs emission slightly blue-shift (349 and $594 \mathrm{~nm}$ ) and another significant peak is found at around $680 \mathrm{~nm}$ (see Fig. 4c). This $680 \mathrm{~nm}$-peak can increase the intensity of red light emission for $\mathrm{N}$-CDs. N-CDs is more chemically stable than P-CDs and F-CDs. It is worth noting that the emission is excitation-wavelengthindependent (see Fig. 4d). ${ }^{26}$ This indicates that N-CDs are homogeneous C-dots and emit at a single dot level. ${ }^{27-29}$

\subsection{Selective Fe(III) sensing}

The selectivity results of N-CDs for 16 kinds of different metal ions are shown in Fig. 4e. Among the tested metal ions, $\mathrm{Fe}^{3+}$ is relatively efficient to quench the $\mathrm{PL}$ of $\mathrm{N}-\mathrm{CDs} . \mathrm{Fe}^{3+}$ sensing experiments by using N-CDs probe were carried out as Fig. 4f. The quenching of N-CDs is linear at the range of $10-300 \mathrm{nmol} \mathrm{L}^{-1}$ of $\mathrm{Fe}^{3+}$, and the LOD is $1.9 \mathrm{nmol} \mathrm{L}^{-1}$.

C-dots were environmental friendly and potential alternative of fluorescent dyes in metal ions detection. The most prominent advantage is that the red-emitting C-dots can be excited at visible region $(400-580 \mathrm{~nm})$ and avoid the use of UV light.

\section{Conclusions}

$p$-Phenylenediamine ( $p$-PD) aqueous solution can be transformed to C-dots (or poly( $p$-PD)) with (or without) acid assistance. Many common inorganic acid, such as $\mathrm{HNO}_{3}, \mathrm{H}_{3} \mathrm{PO}_{4}$ and $\mathrm{HF}$, can efficiently help to synthesize red-emitting C-dots. The red-emission of $p$-PD-based C-dots can be enhanced by strong acid (such as $\mathrm{HNO}_{3}$ ). N-CDs, prepared with the assistance of $\mathrm{HNO}_{3}$, have a wide linear range with a lower LOD for $\mathrm{Fe}^{3+}$ sensing. The selectivity could be further improved for future applications. QYs and the selectivity are two key challenges for $\mathrm{N}$-CDs applied in metal ions detection. Introducing the third reactants, which contain amino- and carboxylicgroups, will be our further research work. Red-emitting Cdots would be also very powerful in the biomedical optical imaging and sensing.

\section{Conflicts of interest}

There are no conflicts to declare. 


\section{Acknowledgements}

This work was supported by the National Natural Science Foundation of China (61675071, 61405062, 61471186 and 91233208), the Pearl River Nova Program of Guangzhou (201710010010), the Guangdong Innovative Research Team Program (201001D00104799318, 2011D039), the Guangdong Natural Science Foundation of Guangdong Province (2014A030313445), the China Postdoctoral Science Foundation (2016M600659, XJ2015018 and 2014T70818), and Joint International Research Laboratory of Optical Information and the Key Laboratory of Optoelectronic Devices and Systems of ministry of Education.

\section{References}

1 N. Durán, M. B. Simões, A. C. M. de Moraes, W. J. Fávaro and A. B. Seabra, J. Biomed. Nanotechnol., 2016, 12, 1323.

2 T. S. Xu, X. Y. Li, Z. H. Xie, X. G. Li and H. Y. Zhang, Microchim. Acta, 2015, 182, 2541.

3 J. C. Ge, Q. Y. Jia, W. M. Liu, L. Guo, Q. Y. Liu, M. H. Lan, H. Y. Zhang, X. M. Meng and P. F. Wang, Adv. Mater., 2015, 27, 4169.

4 L. Bao, C. Liu, Z. L. Zhang and D. W. Pang, Adv. Mater., 2015, 27, 1663.

5 M. Vedamalai, A. P. Periasamy, C. W. Wang, Y. T. Tseng, L. C. Ho, C. C. Shih and H. T. Chang, Nanoscale, 2014, 6, 13119.

6 S. L. Hu, Z. J. Wei, Q. Chang, A. Trinchi and J. L. Yang, Appl. Surf. Sci., 2016, 378, 402.

7 P. Mirtchev, E. J. Henderson, N. Soheilnia, C. M. Yip and G. A. Ozin, J. Mater. Chem., 2011, 22, 1265.

8 X. Y. Xu, R. Ray, Y. L. Gu, H. J. Ploehn, L. Gearheart, K. Raker and W. A. Scrivens, J. Am. Chem. Soc., 2004, 126, 12736.

9 S. N. Baker and G. A. Baker, Angew. Chem., Int. Ed., 2010, 49, 6726.

10 S. J. Zhu, Y. B. Song, X. H. Zhao, J. R. Shao, J. H. Zhang and B. Yang, Nano Res., 2015, 8, 355.

11 J. Yu, N. Song, Y. K. Zhang, S. X. Zhong, A. J. Wang and J. R. Chen, Sens. Actuators, B, 2015, 214, 29.

12 Y. Liu, Y. N. Liu, M. Park, S. J. Park, Y. F. Zhang, M. R. Akanda, B. Y. Park and H. Y. Kim, Carbon Lett., 2017, 21, 61.
13 B. S. B. Kasibabu, S. L. D'souza, S. Jha and S. K. Kailasa, J. Fluoresc., 2015, 25, 803.

14 V. N. Mehta, S. Jha and S. K. Kailasa, Mater. Sci. Eng., C, 2014, 38, 20.

15 H. Zhang, Y. Wang, D. Wang, Y. B. Li, P. Liu, H. G. Yang, T. C. An, Z. Y. Tang and H. J. Zhao, Small, 2014, 10, 3371.

16 Y. W. Zheng, D. Yang, X. Wu, H. R. Yan, Y. C. Zhao, B. Feng, K. Duan, J. Weng and J. X. Wang, RSC Adv., 2015, 5, 90245.

17 K. Jiang, S. Sun, L. Zhang, Y. Lu, A. G. Wu, C. Z. Cai and H. W. Lin, Angew. Chem., Int. Ed., 2015, 54, 5360.

18 L. Song, Y. Y. Cui, C. F. Zhang, Z. B. Hu and X. F. Liu, RSC $A d v .$, 2016, 6, 17704.

19 H. Ding, S. B. Yu, J. S. Wei and H. M. Xiong, ACS Nano, 2016, 10, 484.

20 P. Wang, P. Y. Xiao, S. X. Zhong, J. R. Chen, H. J. Lin and X. L. Wu, J. Mater. Chem. A, 2016, 4, 15450.

21 M. Grabolle, M. Spieles, V. Lesnyak, N. Gaponik, A. Eychmüller and U. Reschgenger, Anal. Chem., 2009, 81, 6285.

22 S. Qu, D. Zhou, D. Li, W. Ji, P. Jing, D. Han, L. Liu, H. Zeng and D. Shen, Adv. Mater., 2016, 28, 3516.

23 L. Tang, R. Ji, X. Li, G. Bai, C. P. Liu, J. Hao, J. Lin, H. Jiang, K. S. Teng and Z. Yang, ACS Nano, 2014, 8, 6312.

24 Z. Gao, Z. Lin, X. Chen, H. Zhong and Z. Huang, Anal. Methods, 2016, 8, 2297.

25 A. M. Craciun, A. Diac, M. Focsan, C. Socaci, K. Magyari, D. Maniu, I. Mihalache, L. M. Veca, S. Astilean and A. Terec, $R S C A d v ., 2016,6,56944$.

26 Z. H. Wen and X. B. Yin, RSC Adv., 2016, 6, 27829.

27 S. Ghosh, A. M. Chizhik, N. Karedla, M. O. Dekaliuk, I. Gregor, H. Schuhmann, M. Seibt, K. Bodensiek, I. A. T. Schaap, O. Schulz, A. P. Demchenko, J. Enderlein and A. I. Chizhik, Nano Lett., 2014, 14, 5656.

28 V. Strauss, J. T. Margraf, C. Dolle, B. Butz, T. J. Nacken, J. Walter, W. Bauer, W. Peukert, E. Spiecker, T. Clark and D. M. Guldi, J. Am. Chem. Soc., 2014, 136, 17308.

29 S. K. Das, Y. Liu, S. Yeom, D. Y. Kim and C. I. Richards, Nano Lett., 2014, 14, 620. 